\title{
Effect of non-utility generator siting on oscillatory stability of Taiwan
} power system

\author{
Tain-Syh Luor and Yuan-Yih Hsu \\ Department of Electrical Engineering. National Taiwan \\ University. Taipei, Taiwan
}

The site specific impact that a non-utility generator (NUG) can have upon the oscillatory stability of the Taiwan power system is investigated. The transmission network in Taiwan has been experiencing porly-damped low frequency oscillations since 1984 due to its longitudinal structure. Therefore, it is essential to evaluate the effect of a non-utility generator on the oscillatory stability of the whole network before it is connected to the system. To do this, an NUG impact evaluation procedure is developed to reach an oscillatory stability inde.x (OSI) which can be employed to evaluate the effect of the NUG at a particular site on system stability. The effectiveness of the proposed impact evaluation procedure is demonstrated by a stability analysis of the Taiwan pow'er system with the NUG installed at different locations. It is expected that the proposed method nill provide a valuable quantitative index which can be used to explore the adequacy of the transmission facilities in the utility when an NUG is initalled at a specific site. Copyright (r. 1996 Elsevier Science Ltd

Keywords: generation planning, oscillatory stability analysis, low frequency oscillations transmission bottleneck

\section{Introduction}

Taiwan Power Company (TPC), a state-owned utility, is the sole electric utility in Taiwan. Under the licence from the government, TPC owns all generating plants and operates the entire transmission and distribution network on the island of Taiwan. Due to the continuing economic growth on the island, TPC load demand has been increasing at an annual rate of around $7 \%$ in the past few years. On the other hand, construction of several major power plants has been delayed or even cancelled due to protests from cnvironmental p:otection groups. As a result, power shortages have been experienced over the past five years. especially during the summer peak. Under

Received 30 January 1996; revised 25 April 1996; accepted 20 June 1996 pressure from law makers to provide a reliable power supply to consumers and to deregulate all governmentowned enterprises including TPC, the Ministry of Economics issued its first announcement to open the electricity generation market to the public in September 1994. Independent power producers (IPP) are now allowed to build non-utility generators (NUG) and sell electricity to TPC. A reviewing committee, comprising members from the government, TPC, universities, and industries is formed to review each NUG project proposed by candidate power producers.

Since the construction and operation of an NUG may cause significant impacts such as air pollution, change in the TPC transmission network loading, risk of system instability, etc., the reviewing committee ought to disapprove those NUG projects which may cause severe environmental pollution or system instability. To help the members in the reviewing committee determine whether a particular NUG project should be approved, ten specific items as described below have been summarized to cover issues related to environmental protection, TPC transmission network security, system stability, etc.

(1) Check if the independent power producer has enough manpower (managers, engineers, technicians, etc.) and has an adequate financial plan.

(2) Check if the independent power producer is able to operate the NUG based on the proposed operation plan and previous operation expcrience.

(3) Check if the IPP is able to get the land for the power plant.

(4) Determine the effect of the proposed NUG on the area generation-load balance.

(5) Check if the scheduled date of commercial operation mects the system requirements and if the type of fuel used by the NUG meets the energy policy.

(6) Check if the pollution from the NUG meets the pollution standard, as required by the Environmental Protection Bureau, and if the residents around the NUG location will accept the NUG project.

(7) Check the fuel supply of the NUG is reliable. 
(8) Determine the effect of the NUG on system fault currents and reactive power requirements.

(9) Check if the current TPC transmission network is capable of transmitting the power from the NUG.

(10) Check if the IPP is able to build the transmission line between the NUG and TPC substations.

Note that the above items cover economical and environmental, as well as technical aspects related to the NUG. In the present work, we are mainly concerned about the effect of the NUG on area generation-load balance as mentioned in item (4) since the area generationload balance affects the system oscillatory instability [1

13] to a great extent. The main reason why we are concerned with the oscillatory instability problem is that TPC has been experiencing inter-area low frequency oscillations since 1984 [2,9-13] due to the longitudinal structure of the EHV transmission networks. In fact, these undamped or poorly-damped oscillations have caused a major threat to the reliable operation of the TPC transmission networks. It is observed from previous recordings that inter-area power flows most affect the damping of the oscillations. In other words, the inter-area oscillations can be avoided if the inter-area power flows can be kept to a minimum. by maintaining the generation-load balance in the three regions (north, center and south) of Taiwan. Based on these findings, it seems natural to favor an NUG project which will help improve the area generation-load balance, since the operation of such an NUG will help reduce the risk of inter-area oscillations. Although generation-load balance is only one of the ten items which must be taken into account by the reviewing committee, we want to provide the members of the reviewing committee with a clear picture of how system security and stability will be severely damaged by an NUG which deteriorates the area generation-load balance and causes inter-area oscillations.
In the literature, the site specific impact that an NUG can have upon the Florida Power Corporation`s ability to sustain interchange power transactions was reported in Reference 14 . The maximum power transfer of the transmission system with and without the NUG were first determined, and the NUG impact on transmission import was computed. It was concluded [14] that the generator location could affect the interchange power transaction capability of the transmission network. In addition, it was recommended that the utility should not bear the adverse burden of an NUG generator connection and the independent power producers should bear the cost for improving the power transfer limit of the transmission network.

Note that load flow, stability and reactive power are taken into account in Reference 14 to find the maximum transfer. In the present work, we propose developing a systematic approach which can be used to evaluate the effect of generator location on the transfer capabilities of the transmission system, as limited by inter-area oscillations, in addition to the factors considered in Reference 14. An impact determination procedure will be developed to reach a quantitative oscillatory stability impact index. It is expected that the proposed oscillatory impact determination procedure can help any utility with a potential inter-area oscillation problem evaluate the sitc impact of an NUG on its transmission network.

The contents of this paper are arranged as follows. In the next section, the study system is briefly described. The transmission bottleneck caused by inter-area oscillations is studied through eigenvalue-eigenvector analysis. This is followed by the NUG siting problem. Potential locations proposed by independent power producers are given and the relative merits of these NUG locations are briefly described. Then, the proposed impact evaluation procedure is presented in Section IV. In Section V, case studies are presented in order to demonstrate the

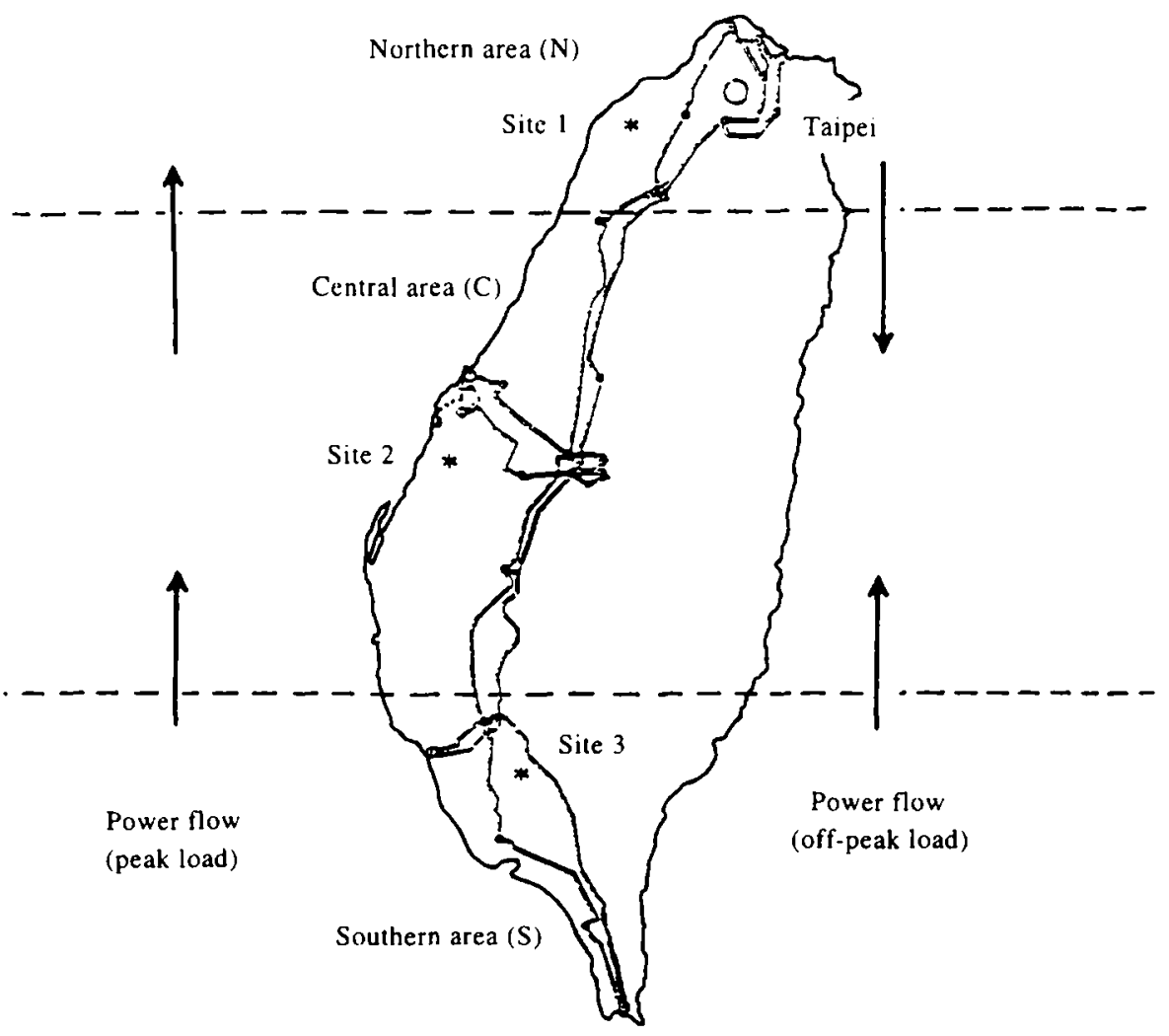

Figure 1. Service area of Taiwan Power Company 
Table 1. Generation bus data

\begin{tabular}{|c|c|c|c|c|}
\hline \multirow[b]{2}{*}{ Area } & \multirow{2}{*}{$\begin{array}{l}\text { Generation } \\
\text { bus number }\end{array}$} & \multirow{2}{*}{$\begin{array}{l}\text { Generator } \\
\text { type }\end{array}$} & \multicolumn{2}{|c|}{$\begin{array}{l}\text { Real power } \\
\text { generation }(\mathrm{MW})\end{array}$} \\
\hline & & & Peak & Off-peak \\
\hline \multirow[t]{15}{*}{ North } & 167 & nuclear & 660 & 660 \\
\hline & 168 & nuclear & 660 & 660 \\
\hline & 169 & nuclear & 985 & 985 \\
\hline & 170 & nuclear & 985 & 985 \\
\hline & 171 & thermal & 114 & 114 \\
\hline & 172 & thermal & 550 & 134.3 \\
\hline & 173 & thermal & 114 & 114 \\
\hline & 174 & thermal & 550 & 114 \\
\hline & 175 & thermal & 35 & 35 \\
\hline & 176 & thermal & 60 & 60 \\
\hline & 177 & thermal & 90 & 90 \\
\hline & 178 & thermal & 300 & 300 \\
\hline & 179 & thermal & 360 & 360 \\
\hline & 180 & thermal & 160 & -- \\
\hline & 181 & hydro & 70 & - \\
\hline \multirow{26}{*}{ Center } & 182 & thermal & 520 & 520 \\
\hline & 183 & thermal & 520 & 520 \\
\hline & 184 & thermal & 520 & 520 \\
\hline & 185 & thermal & 520 & 520 \\
\hline & 186 & thermal & 278 &.- \\
\hline & 187 & thermal & 30 & - \\
\hline & 188 & thermal & 220 & - \\
\hline & 189 & thermal & 220 & \\
\hline & 190 & thermal & 220 & - \\
\hline & 191 & thermal & 300 & - \\
\hline & 192 & thermal & 300 & - \\
\hline & 193 & PS & 150 & -240 \\
\hline & 194 & PS & 150 & -240 \\
\hline & 195 & PS & 150 & -240 \\
\hline & 196 & PS & 150 & -240 \\
\hline & 197 & PS & 270 & -260 \\
\hline & 198 & PS & 270 & -260 \\
\hline & 199 & PS & 270 & -260 \\
\hline & 200 & hydro & - & - \\
\hline & 201 & hydro & 100 & . \\
\hline & 202 & hydro & 100 & - \\
\hline & 203 & hydro & 239.5 & 173.8 \\
\hline & 204 & hydro & 210 & - \\
\hline & 205 & hydro & 40 & - \\
\hline & 206 & hydro & 100 & 60 \\
\hline & 207 & hydro & 20 & - \\
\hline \multirow[t]{16}{*}{ South } & 208 & nuclear & 951 & 951 \\
\hline & 209 & nuclear & 951 & 951 \\
\hline & 210 & thermal & 80 & - \\
\hline & 211 & thermal & 550 & 550 \\
\hline & 212 & thermal & 550 & 550 \\
\hline & 213 & thermal & 624 & 624 \\
\hline & 214 & thermal & 624 & 624 \\
\hline & 215 & thermal & 300 & 300 \\
\hline & 216 & thermal & 330 & 330 \\
\hline & 217 & thermal & 82 & 82 \\
\hline & 218 & thermal & 550 & 110 \\
\hline & 219 & thermal & 533 & 110 \\
\hline & 220 & thermal & 80 & - \\
\hline & 221 & thermal & 179 & - \\
\hline & 222 & thermal & 179 & - \\
\hline & 223 & hydro & 115 & 15 \\
\hline
\end{tabular}

PS: pumped-storage

-: off-line unit

203: swing generator effectiveness of the proposed impact evaluation procedure. Discussion of the results is presented in Section VI.

\section{Description of the study system}

The service area of TPC covers the entire island of Taiwan, a distance of $400 \mathrm{~km}$ from the north to the south and $120 \mathrm{~km}$ from the west to the east. As shown in Figure 1, the island is divided into three areas, i.e., the northern area $(\mathrm{N})$, the central area $(\mathrm{C})$, and the southern area (S). The three areas are connected together via $345 \mathrm{kV}$ trunk lines. Since the system is longitudinal in nature, it is vulnerable to inter-area low frequency oscillations [2-8], especially when the trunk lines are heavily loaded.

The generation bus number, geographical area, and type of generator are listed in Table 1 . Note that there are four nuclear units $(167-170)$ and some thermal units in the north. Most hydro units, including several pumpedstorage units, are located in the central area. In addition to the hydro units, there are some thermal units in the center. In the south, there are two nuclear units and several thermal units. A major load center is located in Taipei, which is the capital of Taiwan.

Figure 2 depicts a typical daily load curve in the summer peak. It is observed from Figure 2 that the peak load $(17824 \mathrm{MW})$ is much higher than the off-peak load $(10165 \mathrm{MW})$ and the load factor is very poor. To improve the load factor, seven pumped-storage units (193-199) have been installed near Sun-Moon Lake in the central area. These pumped-storage units consume the excess power from the nuclear units through pump operation at night and provide load demand through generating operation during peak hours.

To examine the generation-load balance in the three areas, the real power generations, load demands, and the surplus (or deficit) powers are listed in Table 2. It is noted that two typical load patterns, one for peak load condition and the other for off-peak load condition, are considered. It is observed from Table 2 that, under peak load conditions, the surplus power ( $3611 \mathrm{MW}$ ) in the south is transmitted to the center and north through $345 \mathrm{kV}$ trunk lines. The seven pumped-storage units are all operated in the generation mode. During the off-peak period, the central area has a deficit power of $3222 \mathrm{MW}$ because the seven pumped-storage units are now operating in the pumping mode. Most of the deficit power comes from the south. In summary, a significant amount of

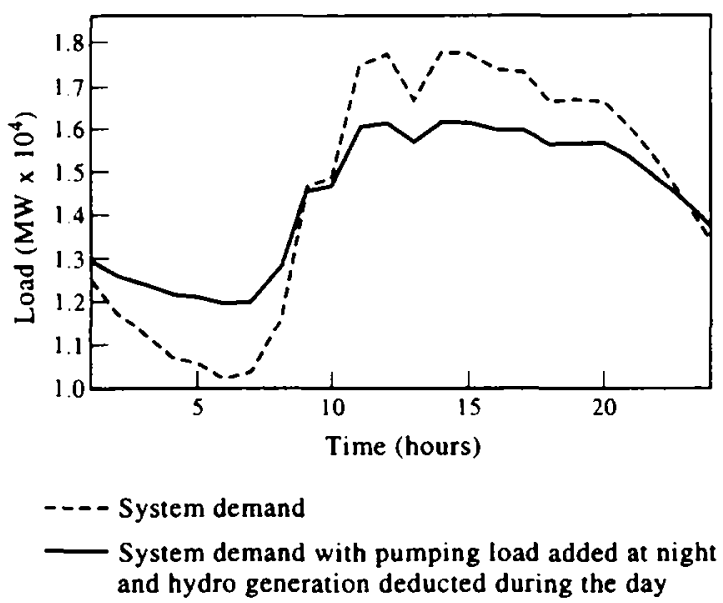

Figure 2. Typical daily load curve of TPC 
Table 2. Real power generations and load demands

\begin{tabular}{|c|c|c|c|c|c|c|}
\hline Case & Area & \multicolumn{2}{|c|}{ Real power generation } & \multicolumn{2}{|c|}{ Load demand } & $\begin{array}{l}\text { Surplus or } \\
\text { deficit }(-) \\
\text { power }(\mathrm{MW})\end{array}$ \\
\hline Peak & $\begin{array}{l}\mathrm{N} \\
\mathrm{C} \\
\mathrm{S} \\
\text { Total }\end{array}$ & $\begin{array}{r}5693 \\
5900 \\
6678 \\
18271\end{array}$ & $\begin{array}{r}31.2 \\
32.3 \\
36.5 \\
100\end{array}$ & $\begin{array}{r}8109 \\
6648 \\
3067 \\
17824\end{array}$ & $\begin{array}{c}45.5 \\
37.3 \\
17.2 \\
100\end{array}$ & $\begin{array}{r}-2416 \\
-748 \\
3611 \\
-\end{array}$ \\
\hline Off-peak & $\begin{array}{l}\text { N } \\
\text { C } \\
\text { S } \\
\text { Total }\end{array}$ & $\begin{array}{c}4611.3 \\
573.8 \\
5197 \\
10382.1\end{array}$ & $\begin{array}{r}44.4 \\
5.5 \\
50.1 \\
100\end{array}$ & $\begin{array}{c}4 \overline{4280.8} \\
3796 \\
2088.6 \\
10165.4\end{array}$ & $\begin{array}{c}42.1 \\
37.3 \\
20.6 \\
100\end{array}$ & $\begin{array}{r}330.5 \\
-3222.2 \\
3108.4 \\
-\end{array}$ \\
\hline
\end{tabular}

power $(3611 \mathrm{MW})$ is transmitted from the south to the center and then to the north during peak hours while a somewhat smaller amount of power $(3108 \mathrm{MW})$ is transmitted to the center during the off-peak period.

Since there are heavy power flows over the inter-area trunk lines, it is essential to examine whether the interarea mode is well-damped. In this work. we compute the eigenvalue. oscillation frequency and normalized generator speeds (eigenvectors) for each electromechanical mode using a modified version of the AESOPS program $[1,15,16]$. Note that the AESOPS program provides us with the eigenvalues and eigenvectors for all the electromechanical modes. Among these modes, the inter-area mode which affects all generators in the three areas of the system usually has the worst damping, based on our previous experience $[2,9.10]$. Thus. this inter-area mode will be of major concern in this work. Table 3 gives the eigenvalues, oscillation frequency. and damping ratio for this mode. It is observed from Table 3 that the inter-area mode is poorly damped under both peak load and offpeak load conditions. The oscillation frequency is around $0.85 \mathrm{~Hz}$ and the real part of the eigenvalues for this mode are -0.059 and -0.0413 for the peak load case and the off-peak load case, respectively.

To examine how the generators in the three areas interact with each other in the inter-area oscillations, Figure $3 a$ and $b$ depicts the cigenvectors for the interarea mode under peak load condition and off-peak load condition, respectively. It is observed from Figure 3 that the generators in the northern area and central area form a group which oscillates with the group of generators in the south. This is a rather interesting observation which should be taken into account in determining proper locations for the NUG because the addition of an NUG in a certain area will not only affect inter-area line flows which, in turn. affect the damping for the inter-area mode, but also affect the way a group of generators oscillates with another. The eigenvalues and eigenvectors for other electromechanical modes are not listed because they have much better damping and do not cause oscillatory instability problems in the study system.

\section{NUG siting problem}

Because running an NUG in Taiwan seems to be highly profitable, at least at the present time, many investors, both local and overseas, have been working on their NLG projects since the government made its announce- ment to open the NUG market in September 1994. Most investors face two major obstacles in their NUG projects: the land and the fuel for the power plant. Since Taiwan is a small, crowded island with more than twenty million people, land is rather scarce and expensive. On the other hand, the fuel for the plant (coal, oil or gas) must be imported from overseas. Thus, a feasible NUG site must have access to the imported fuel and must be away from towns in order to get relatively cheap land and to avoid protest from the neighbouring residents. In fact, several of TPC's plants have been forced to shut down many times duc to the protest from nearby residents. Based on these considerations, most investors may wish to put their NUGs in industrial zones where their own factories are located. In this way, they can get inexpensive land for the

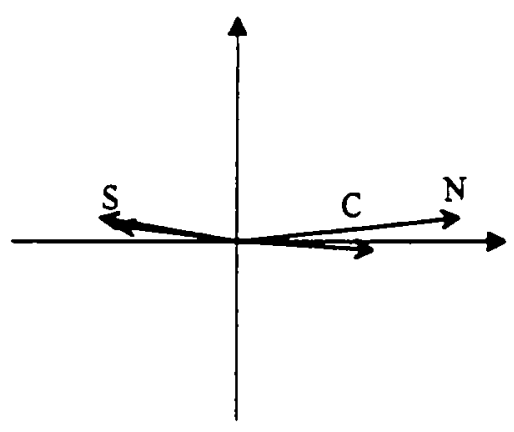

(a) peak load condition

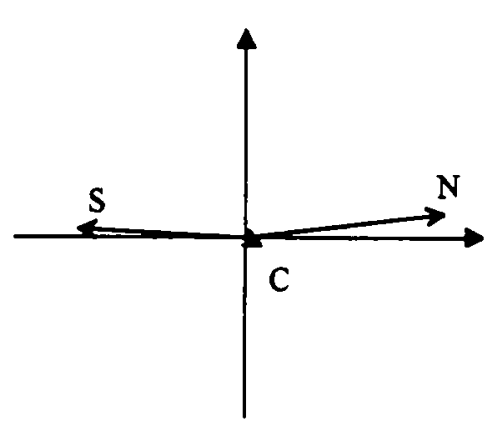

(b) off-peak load condition

Figure 3. Eigenvectors for the inter-area mode. (a) Peak load condition and (b) off-peak load condition 
Table 3. Eigenvalues and eigenvectors* (normalized speed deviation) for the inter-area mode

\begin{tabular}{|c|c|c|c|}
\hline Peak case & & \multicolumn{2}{|l|}{ Off-peak case } \\
\hline Eigenvalues & $-0.059 \pm j 5.34$ & Eigenvalues & $-0.0413 \pm j 5.392$ \\
\hline Oscillation frequency & 0.85 & Oscillation frequency & 0.858 \\
\hline Damping ratio & 0.01 & Damping ratio & 0.0076 \\
\hline $\begin{array}{l}\text { Generation bus } \\
\text { number }\end{array}$ & $\begin{array}{l}\text { Normalized speed } \\
\text { deviation }\end{array}$ & $\begin{array}{l}\text { Generation bus } \\
\text { number }\end{array}$ & $\begin{array}{l}\text { Normalized speed } \\
\text { deviation }\end{array}$ \\
\hline 167 & $0.76+j 0.02$ & 167 & $0.74-j 0.03$ \\
\hline 168 & $0.76+j 0.02$ & 168 & $0.74-j 0.03$ \\
\hline 169 & $1.00+j 0.09$ & 169 & $1.00+j 0.05$ \\
\hline 170 & $1.00+j 0.09$ & 170 & $1.00+j 0.05$ \\
\hline 171 & $0.78+j 0.04$ & 171 & $0.73-j 0.01$ \\
\hline 172 & $0.86+j 0.01$ & 172 & $0.74-j 0.01$ \\
\hline 173 & $0.78+j 0.04$ & 173 & $0.73-j 0.01$ \\
\hline 174 & $0.86+j 0.01$ & 174 & $0.73-j 0.01$ \\
\hline 175 & $0.63+j 0.04$ & 175 & $0.61+j 0.00$ \\
\hline 176 & $0.72+j 0.05$ & 176 & $0.73+j 0.02$ \\
\hline 177 & $0.76+j 0.05$ & 177 & $0.77+j 0.01$ \\
\hline 178 & $0.65+j 0.00$ & 178 & $0.63-j 0.04$ \\
\hline 179 & $0.64+j 0.02$ & 179 & $0.61-j 0.02$ \\
\hline 180 & $0.59+j 0.01$ & 203 & $0.16-j 0.02$ \\
\hline 181 & $0.61-j 0.01$ & 208 & $-0.89+j 0.02$ \\
\hline 182 & $0.12+j 0.00$ & 209 & $-0.89+j 0.02$ \\
\hline 183 & $0.12+j 0.00$ & 211 & $-0.66-j 0.01$ \\
\hline 184 & $0.12+j 0.00$ & 212 & $-0.66-j 0.01$ \\
\hline 185 & $0.12+j 0.00$ & 213 & $-0.60+j 0.01$ \\
\hline 187 & $0.67-j 0.02$ & 214 & $-0.60+j 0.01$ \\
\hline 188 & $0.58-j 0.03$ & 215 & $-0.79+j 0.00$ \\
\hline 189 & $0.58-j 0.03$ & 216 & $-0.77+j 0.00$ \\
\hline 190 & $0.58-j 0.03$ & 217 & $-0.80-j 0.05$ \\
\hline 191 & $0.58-j 0.04$ & 218 & $-0.64-j 0.05$ \\
\hline 192 & $0.58-j 0.04$ & 219 & $-0.64-j 0.05$ \\
\hline 193 & $0.16-j 0.06$ & 223 & $-0.80+j 0.07$ \\
\hline 194 & $0.16-j 0.06$ & & \\
\hline 195 & $0.16-j 0.06$ & & \\
\hline 196 & $0.16-j 0.06$ & & \\
\hline 197 & $0.11-j 0.02$ & & \\
\hline 198 & $0.11-j 0.02$ & & \\
\hline 199 & $0.11-j 0.02$ & & \\
\hline 201 & $0.26-j 0.02$ & & \\
\hline 202 & $0.31-j 0.01$ & & \\
\hline 203 & $0.35-j 0.04$ & & \\
\hline 204 & $0.41-j 0.05$ & & \\
\hline 205 & $0.10+j 0.01$ & & \\
\hline 207 & $-0.13+j 0.01$ & & \\
\hline 208 & $-0.63+j 0.07$ & & \\
\hline 209 & $-0.63+j 0.07$ & & \\
\hline 210 & $-0.66-j 0.01$ & & \\
\hline 211 & $-0.45+j 0.04$ & & \\
\hline 212 & $-0.45+j 0.04$ & & \\
\hline 213 & $-0.42+j 0.05$ & & \\
\hline 214 & $-0.42-j 0.05$ & & \\
\hline 215 & $-0.58+j 0.06$ & & \\
\hline 216 & $-0.59+j 0.06$ & & \\
\hline 217 & $-0.61+j 0.02$ & & \\
\hline 218 & $-0.67-j 0.08$ & & \\
\hline 219 & $-0.68-j 0.08$ & & \\
\hline 220 & $-0.54+j 0.00$ & & \\
\hline 221 & $-0.48-j 0.06$ & & \\
\hline 222 & $-0.48+j 0.06$ & & \\
\hline 223 & $-0.91+j 0.00$ & & \\
\hline
\end{tabular}


NUG. Once approved, the NUG provides electricity service to the local factories and sells the excess power to TPC. Up to now, three possible sites (Site 1, Site 2, and Site 3, as shown in Figure 1) have been selected as candidate locations for the NUG by the investors. It is noted that, among the three possible locations for the NUG. Site 1, which is located in the northern area, is closest to the load center in Taipei. Site 2, in the central area, is close to a large petro-chemical plant. while Site 3 in the southern area is close to a large steel mill.

It was mentioned in last section that undamped interarea low frequency oscillations would be observed when the inter-area power flows are heavy. Since the addition of an NUG at different locations will have a different impact upon the inter-area power flows, it is obvious that the NUG location will affect the damping of the interarea oscillations to a great extent. Because the damping of inter-area oscillations has a significant impact on the reliable operation of the whole TPC, it is essential to develop a procedure to evaluate quantitatively the impact of NUG location on the damping of inter-area oscillations. This motivates the development of the impact evaluation procedure in the next section.

\section{The proposed NUG impact evaluation procedure}

The impact of a generator installation at a given site can be determined using the load flow program and the AESOPS program. The studies are evaluated at representative system conditions and the average impact found. This impact gives an index of how much the damping of the inter-area mode will improve (when the index is positive) or deteriorate (when the index is nega-

Table 4. Summary of the generated powers of the units redispatched

(a) peak load case

\begin{tabular}{lllll}
\hline Generator & \multicolumn{4}{l}{ NUG capacity } \\
number & Area & $1000 \mathrm{MW}$ & $1500 \mathrm{MW}$ & $2000 \mathrm{MW}$ \\
\hdashline$-\mathrm{C}$ & $\mathrm{C}$ & 245 & 299.76 & 273 \\
203 & $\mathrm{~N}$ & & - & 174 \\
178 & $\mathrm{~N}$ & & 399.03 & 114 \\
172 & $\mathrm{~N}$ & 413.03 & 64 & 64 \\
174 & $\mathrm{~S}$ & 110 & 110 & 110 \\
218 & $\mathrm{~S}$ & 110 & 110 & 110 \\
219 & $\mathrm{M}$ & & \\
\hline
\end{tabular}

\begin{tabular}{|c|c|c|c|c|}
\hline \multicolumn{5}{|c|}{ (b) Off-peak load case } \\
\hline \multirow{2}{*}{$\begin{array}{l}\text { Generator } \\
\text { number }\end{array}$} & \multirow[b]{2}{*}{ Area } & \multicolumn{3}{|c|}{ NUG capacity } \\
\hline & & $1000 \mathrm{MW}$ & $1500 \mathrm{MW}$ & $2000 \mathrm{MW}$ \\
\hline 203 & $\mathrm{C}$ & 218 & 253 & 280 \\
\hline 213 & $\mathbf{S}$ & - & - & 355 \\
\hline 182 & $\mathrm{C}$ & - & 396.3 & 165 \\
\hline 183 & $\mathrm{C}$ & - & 165 & 165 \\
\hline 184 & $\mathrm{C}$ & 141 & 120 & 120 \\
\hline 185 & $\mathrm{C}$ & 120 & 120 & 120 \\
\hline 178 & $\mathrm{~N}$ & 99 & 99 & 99 \\
\hline 172 & $N$ & 114 & 114 & 114 \\
\hline
\end{tabular}

-: the same as in Table 1 tive) when the NUG is added to the system. The NUG impact evaluation procedure is as follows

Step 1: Run load flow program for the TPC system without the generator to get inter-area power flows and use the AESOPS program to obtain the eigenvalues and eigenvector for the inter-area mode without the NUG.

Step 2: Add the non-utility generator to the TPC system. Since TPC must purchase the power generated by the NUG, redispatch the thermal units of TPC. For convenience, the power generated by the hydro units and nuclear units is assumed to remain unchanged.

Step 3: Run load flow program and AESOPS program to get the inter-area power flows and the eigenvalues and eigenvector for the inter-area mode with NUG.

Step 4: Compare the inter-area power flows and eigenvectors for the system with and without the NUG.

Step 5: Compute the damping ratios of the inter-area modes for the system with and without the NUG.

Step 6: Determine the oscillatory stability impact (OSI) by:

Table 5. Real power generations

\begin{tabular}{|c|c|c|c|c|}
\hline & & & & \\
\hline $\begin{array}{l}\text { capacity } \\
(\mathrm{MW})\end{array}$ & $\begin{array}{l}\text { NUG } \\
\text { site }\end{array}$ & Area & $\begin{array}{l}\text { Peak } \\
\text { load case }\end{array}$ & $\begin{array}{l}\text { Off-peak } \\
\text { load case }\end{array}$ \\
\hline 1000 & $1(N)$ & $\begin{array}{l}N \\
C \\
S\end{array}$ & $\begin{array}{r}-1553 \\
-748 \\
2748\end{array}$ & $\begin{array}{c}1109.2 \\
-4003 \\
3108.4\end{array}$ \\
\hline 1000 & $2(\mathrm{C})$ & $\begin{array}{l}N \\
C \\
S\end{array}$ & $\begin{array}{r}-2553 \\
252 \\
2748\end{array}$ & $\begin{array}{r}109.2 \\
-3000.4 \\
3108.4\end{array}$ \\
\hline 1000 & $3(\mathrm{~S})$ & $\begin{array}{l}\mathrm{N} \\
\mathrm{C} \\
\mathrm{S}\end{array}$ & $\begin{array}{r}-2553 \\
-748 \\
3748\end{array}$ & $\begin{array}{l}109.2 \\
3957 \\
4108.4\end{array}$ \\
\hline 1500 & $l(N)$ & $\begin{array}{l}N \\
C \\
S\end{array}$ & $\begin{array}{r}-1553 \\
-748 \\
2748\end{array}$ & $\begin{array}{c}1609.2 \\
-4496 \\
3108.4\end{array}$ \\
\hline 1500 & $2(\mathrm{C})$ & $\begin{array}{l}N \\
C \\
S\end{array}$ & $\begin{array}{r}-3035 \\
752 \\
2748\end{array}$ & $\begin{array}{r}109.2 \\
-2297.1 \\
3108.4\end{array}$ \\
\hline 1500 & $3(\mathrm{~S})$ & $\begin{array}{l}N \\
C \\
S\end{array}$ & $\begin{array}{r}-3035 \\
-748 \\
4248\end{array}$ & $\begin{array}{r}109.2 \\
-4421.1 \\
4608.4\end{array}$ \\
\hline 2000 & $1(N)$ & $\begin{array}{l}N \\
C \\
S\end{array}$ & $\begin{array}{r}-1539 \\
-762 \\
2748\end{array}$ & $\begin{array}{r}2109.2 \\
-4722.5 \\
2839.7\end{array}$ \\
\hline 2000 & $2(\mathrm{C})$ & $\begin{array}{l}N \\
C \\
S\end{array}$ & $\begin{array}{r}-3539 \\
1238 \\
2748\end{array}$ & $\begin{array}{r}109.2 \\
-2730.8 \\
2839.7\end{array}$ \\
\hline 2000 & $3(\mathrm{~S})$ & $\begin{array}{l}N \\
C \\
S\end{array}$ & $\begin{array}{r}-3539 \\
-762 \\
4748\end{array}$ & $\begin{array}{r}109.2 \\
-4625.5 \\
4839.7\end{array}$ \\
\hline
\end{tabular}


Table 6(a) Summary of oscillatory stability impact for the peak load case

\begin{tabular}{|c|c|c|c|c|c|}
\hline $\begin{array}{l}\text { NUG capacity } \\
(\mathrm{MW})\end{array}$ & $\begin{array}{l}\text { NUG } \\
\text { site }\end{array}$ & $\begin{array}{l}\text { Real part of } \\
\text { eigenvalue }\end{array}$ & $\begin{array}{l}\text { Frequency } \\
(\mathrm{Hz})\end{array}$ & $\begin{array}{l}\text { Damping } \\
\text { ratio }\end{array}$ & OSI(\%) \\
\hline & original & -0.059 & 0.85 & 0.011 & - \\
\hline 1000 & $\begin{array}{l}1(\mathrm{~N}) \\
2(\mathrm{C}) \\
3(\mathrm{~S})\end{array}$ & $\begin{array}{l}-0.1125 \\
-0.1122 \\
-0.099\end{array}$ & $\begin{array}{l}0.8797 \\
0.8855 \\
0.8506\end{array}$ & $\begin{array}{l}0.0205 \\
0.02016 \\
0.0185\end{array}$ & $\begin{array}{l}86.36 \\
83.27 \\
68.18\end{array}$ \\
\hline 1500 & $\begin{array}{l}1(N) \\
2(C) \\
3(S)\end{array}$ & $\begin{array}{l}-0.1212 \\
-0.1212 \\
-0.1093\end{array}$ & $\begin{array}{l}0.8856 \\
0.8961 \\
0.8417\end{array}$ & $\begin{array}{l}0.0217 \\
0.02166 \\
0.02028\end{array}$ & $\begin{array}{l}97.27 \\
96.9 \\
84.36\end{array}$ \\
\hline 2000 & $\begin{array}{l}1(\mathrm{~N}) \\
2(\mathrm{C}) \\
3(\mathrm{~S})\end{array}$ & $\begin{array}{l}-0.124 \\
-0.1258 \\
-0.1091\end{array}$ & $\begin{array}{l}0.8865 \\
0.9011 \\
0.8252\end{array}$ & $\begin{array}{l}0.0222 \\
0.0222 \\
0.021\end{array}$ & $\begin{array}{c}101.81 \\
101.81 \\
90.9\end{array}$ \\
\hline \multicolumn{6}{|c|}{ (b) Summary of oscillatory stability impact for the off-peak case } \\
\hline \multirow[t]{2}{*}{$\begin{array}{l}\text { NUG capacity } \\
\text { (MW) }\end{array}$} & $\begin{array}{l}\text { NUG } \\
\text { site }\end{array}$ & $\begin{array}{l}\text { Real part of } \\
\text { eigenvalue }\end{array}$ & $\begin{array}{l}\text { Frequency } \\
(\mathrm{Hz})\end{array}$ & $\begin{array}{l}\text { Damping } \\
\text { ratio }\end{array}$ & $\mathrm{OSI}(\%)$ \\
\hline & original & -0.0413 & 0.858 & 0.0076 & - \\
\hline 1000 & $\begin{array}{l}1(\mathrm{~N}) \\
2(\mathrm{C}) \\
3(\mathrm{~S})\end{array}$ & $\begin{array}{l}-0.0536 \\
-0.0526 \\
-0.017\end{array}$ & $\begin{array}{l}0.8614 \\
0.8717 \\
0.824\end{array}$ & $\begin{array}{l}0.0099 \\
0.0096 \\
0.00328\end{array}$ & $\begin{array}{r}30.26 \\
26.31 \\
-56.84\end{array}$ \\
\hline 1500 & $\begin{array}{l}1(N) \\
2(C) \\
3(S)\end{array}$ & $\begin{array}{r}-0.0548 \\
-0.0535 \\
0.0036\end{array}$ & $\begin{array}{l}0.856 \\
0.8727 \\
0.7969\end{array}$ & $\begin{array}{r}0.01018 \\
0.00976 \\
-0.00072\end{array}$ & $\begin{array}{r}33.94 \\
28.36 \\
-109.4\end{array}$ \\
\hline 2000 & $\begin{array}{l}1(N) \\
2(C) \\
3(S)\end{array}$ & $\begin{array}{r}-0.0576 \\
-0.0565 \\
0.0179\end{array}$ & $\begin{array}{l}0.8566 \\
0.88 \\
0.7782\end{array}$ & $\begin{array}{c}0.0107 \\
0.0102 \\
-0.00366\end{array}$ & $\begin{array}{r}40.78 \\
34.21 \\
-148.16\end{array}$ \\
\hline
\end{tabular}

OSI $(\%$ impact $)=$

damping ratio with $\mathrm{NIJG}$ - damping ratio without NUG damping, ratio without NUG

$$
\times 100 \%
$$

Step 7: Repeat Steps 2-6 for various NUG capacities.

\section{Case studies}

To demonstrate the effectiveness of the proposed NUG impact evaluation procedure and to examine which one of the three potential NUG sites in Figure 1 is the most desirable, several case studies were conducted on the study system described :n Section II. Among them, only the results from two exireme cases are presented due to limited space.

Before the NUG is added, the real power generations and load demands for the three areas of Taiwan for the two cases under study are summarized in Table 2 for the peak load and off-peak load cases. The eigenvalues and damping ratios are listed in Table 3 . The eigenvectors are depicted in Figure 3.

As we mentioned earlier, three possible NUG sites, Site 1 in the north, Site 2 in the center, and Site 3 in the south will be considered. For each NUG location, three different generator capacities, i.e. 1000,1500 and $2000 \mathrm{MW}$, will be studied.

As pointed out in Step 2 of the evaluation procedure, the thermal units must be redispatched when the NUG is added to the system. Table 4 summarizes the generated powers of the units redispatched. Those units whose generated powers remain unchanged are not listed.
It is noted that the dispatch results are the same for the same NUG capacity regardless of the NUG site.

In order to estimate the area power balance for each case, the surplus (or deficit) powers in the three areas are listed in Table 5 for the peak load and off-peak load cases. Note that the results in Table 5 are summarized from the results in Tables 2 and 4. For example, when installing a 2000 MW NUG in the peak load case, units $172,174,178$, 218 and 219 are redispatched (Table 4 ). If the NUG is located in the northern or central area, the power generation in the southern area will be reduced by $863 \mathrm{MW}$ because the outputs of units 218 and 219 in the south are redispatched from $550 \mathrm{MW}$ and $533 \mathrm{MW}$, respectively, to $110 \mathrm{MW}$. As a result, the surplus power in the south will be reduced from $3611 \mathrm{MW}$ (Table 2) to $2748 \mathrm{MW}$ (Table 5). Using the AESOPS program, we can obtain the eigenvalues for the inter-area modes. Then the damping

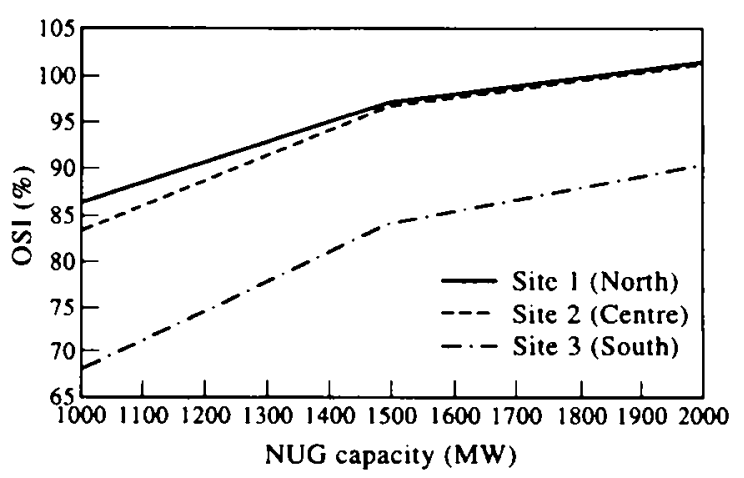

Figure 4. Oscillatory stability impact (OSI) as a function of NUG capacity (peak load case) 


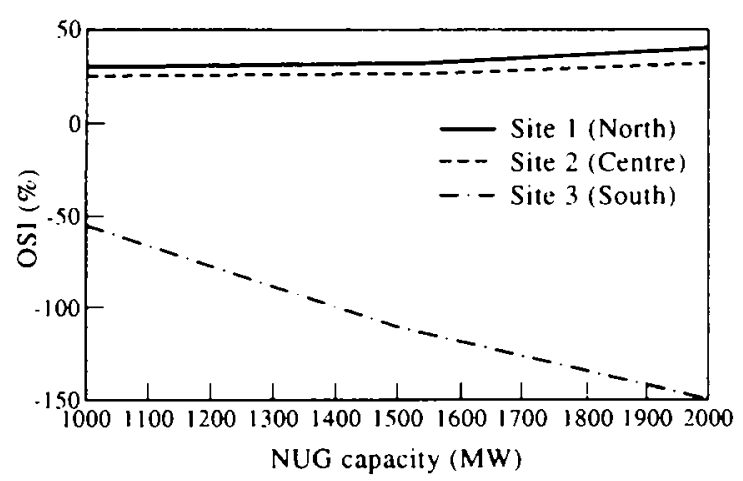

Figure 5. Oscillatory stability impact (OSI) as a function of NUG capacity (off-peak load case)

ratio and oscillatory stability impact (OSI) for each case can be figured out. Table $6 \mathrm{a}$ and $\mathrm{b}$ lists the results for the peak load and off-peak load case, respectively. The oscillatory stability impacts for each NUG site with different capacities are depicted in Figures 4 and 5 for the peak load and off-peak load case, respectively.

\section{Discussions}

Based on the results in Tables 4-6 and Figures 4 and 5, the following observations can be made.

(1) In the case of peak load, oscillatory stability impacts for the three possible sites are all positive. In other words, the damping for the inter-area mode will be improved no matter where the NUG is installed. To see why the damping is improved by the NUG, let us examine the generator output powers redispatched by the NLG as shown in Table 4a and the area power balance in Table 5 . It has been pointed out in Section II that heavy power flows over the trunk lines from the south to the center will cause undamped inter-area oscillations. The system without the NUG has a surplus power of $3611 \mathrm{MW}$ in the south. When a $2000 \mathrm{MW} N \mathrm{MG}^{\mathrm{G}}$ is installed in the northern or the central area, the surplus power in the south is reduced to $2748 \mathrm{MW}$, resulting in a decrease in the trunk line flow northward, which in turn, causes an improvement in the damping ratio as revealed by the positive OSI for the two cases. On the other hand, when a $2000 \mathrm{MW}$ NUG is installed in the southern area, the surplus power in the south is increased to $4748 \mathrm{MW}$. The trunk line flow northward is increased but the OSI is also positive in this case. In fact, the damping ratio in this case is only slightly smaller than that for the case where the NUG is installed in the northern or central area. Why does an increase in trunk line flow cause an improvement in the damping ratio for inter-area oscillation? Recall that, in Reference 11 , it was pointed out that, in addition to inter-area line flows, the output powers of some key generators would affect the damping for the inter-area mode. In the present study, units 218 and 219 in the south have been identified as the major key generators based on the results from numerous test runs. It is also observed that system damping will be increased when the output powers of units 218 and 219 are decreased. In the present case, the output powers of units 218 and 219 are decreased from $550 \mathrm{MW}$ and $533 \mathrm{MW}$, respectively, to $110 \mathrm{MW}$ for both units (Table 1 and Table 4a) when the NUG is added to the system. Thus the decrease in the output power of these major key generators helps to improve the damping for the inter-area mode. In summary, the oscillatory stability impact seems to be the same no matter where the NLG is installed in the peak-load case.

(2) Consider the peak load case again. It seems that the OSI is somewhat improved when the NUG capacity is increased from 1000 to $2000 \mathrm{MW}$. This is due to the decrease in the output powers of the two minor key generators, units 172 and 174 . When the output powers of these two generators are reduced, the damping for the inter-area oscillation will be somewhat improved, based on previous test results.

(3) In the case of off-peak load, most of the generators redispatched when the NUG is added to the system are located in the central area. The major key generators (units 218 and 219) are not redispatched. The damping for the inter-area mode is mainly determined by the trunk line flow from the south to the center and the power output of the minor key generator, unit 172.

(4) Consider again the case of off-peak load. When a $2000 \mathrm{MW}$ NUG is installed in the northern or central area, the surplus power in the south is reduced from $3108 \mathrm{MW}$ (Table 2) to $2839 \mathrm{MW}$ (Table 5). Therefore, the damping ratio for the inter-area mode is improved from 0.0076 to 0.0107 and 0.0102 (Table $6 \mathrm{~b}$ ). respectively. The oscillatory stability impacts are 40.78 and 34.21 for the two cases, respectively. When the NUG is installed in the southern area, the surplus power in the south is increased from 3108 to $4839.7 \mathrm{MW}$. Since the surplus power increase will cause an increase in trunk line flow from the southern to the central area, it is reasonable to see a deterioration in the system damping ratio (from 0.0076 to $-0.00336)$. The OSI is negative $(-148.16)$ in this case. which means that the NUG will have a negative impact on the system stability. The general trend, that an NUG installed in the north or center has a positive OSI and that one installed in the south has a negative OSI, applies equally well when the NLG capacity is reduced from 2000 to 1500 or $1000 \mathrm{MW}$.

(5) As far as the cigenvectors for the inter-area mode for the system with an NUG are concerned, they are essentially similar to those for the system without NUG in both the peak-load and off-peak load case. In other words, the generators in the north and center form a group which oscillates with another group of generators in the south. These eigenvectors are not presented due to limited space.

\section{Conclusions}

An NUG impact evaluation procedure has been developed to evaluate the impact of an NUG at a specific site, on the damping of the inter-area mode. Our primary concern is to determine whether an NUG at a specific site will cause undamped or poorly-damped inter-area oscillations, since such oscillations may cause severe damage to the whole transmission network. An oscillatory stability index is defined for the purpose of evaluating the NUG site impact.

Since the impact of an NUG on system damping is a function of system loading conditions, it is recommended that evaluations on several extreme cases, e.g., peak load condition and off-peak load conditions, be made first. If the damping ratio for a particular case is too small (e.g. less than 0.01 ) or even negative. the specific NUG site should be avoided and further analyses on other system conditions are not necessary. If the damping ratios for all cases are satisfactory, the average impact can be figured 
out. The NUG site wi:h a higher average oscillatory stability impact will give more contributions to system damping and can be regarded as a better NUG site as far as oscillatory stability is concerned.

The proposed oscillatory stability impact evaluation procedure can be applied to any utility with a potential oscillatory stability problem to determine if a specific NUG site is acceptable c.s far as the transfer capability of the utility is concerned. It is essential for the utility to conduct such evaluation since, as mentioned in Reference 14 , the utility stockholders should not bear the adverse burden of the NUG generation connection.

\section{Acknowledgements}

The authors would like to express their sincere gratitude to the people in the System Operation and System Planning Departments of the Taiwan Power Company for providing us with the system data and operating experience. Financial support given to this work by the National Science Council of R.O.C., under contract number NSC 84-2213E002-069 is appreciated.

\section{References}

1 Byerly, R. T.. Sherman, D. E. and Bennon. R. J., Frequency domain analysis of low frequency oscillations in large electric power systems. EPRI Research Project 744-1, 1982.

2 Hsu. Y. Y.. Shyue, S. W. and Su, C. C., Low frequency oscillation in longitudinal power systems: experience with dynamic stability of Taiwan power system. IEEE Transactions on PWRS. 1987. 2(1), 92100 .

3 Messina. A. R., Experience with the analysis of small signal stability in longitudirial systems: a case study with the Mexican interconnected system. International Journal of Electrical Power and Energy Systems, 1995. 17(5), 291299.

4 Klein. M., Rogers. G. J. and Kundur, P., A fundamental study of inter-area oscillations in power systems. IEEE Transactions on PWRS, 1991, 6(3), 914921.

$5 \mathrm{Hsu}, \mathrm{Y} . \mathrm{Y}$. and Wu. C. H.. Experience with dynamic equivalencing of a longitudinal power system. International
Journal of Electrical Power and Energy Systems. 1991. 13(1), 2-8.

6 Dandeno, P. L., General overview of steady-state (small signal) stability in bulk electricity systems, a North American perspective. International Journal of Electrical Power and Energy' Systems, 1982, 4(4), 253264.

7 Zhou, E. Z., Power oscillation flow study of electric power systems. International Journal of Electrical Power and Energy Systems, 1995. 17(2), 143-150.

8 Da-zhong, F., Chung, T. S. and David, A. K.. Inter-area mode transient stability estimation. International Journal of Electrical Power and Energy Systems, 1995, 17(5), 305-312.

9 Chang, C. L.. Liu, A. S. and Huang, C. T., Oscillatory stability analysis using real-time measured data. IEEE Transactions on PWRS, 1993, 8(3) 823-829.

10 Chang, C. L., Liu, C. S. and Ko, C. K., Experience with power system stabilizers in a longitudinal power system. Paper 94 SM 529-8, presented at the IEEE/PES Summer Meeting, 1994.

11 Hsu, Y. Y. and Su. C. C., A rule-based expert system for steady-state stability analysis. IEEE Transactions on PWRS, 1991, 6(2), 771777.

$12 \mathrm{Hsu}, \mathrm{Y}$. Y. and Su, C. C., Application of power system stabilizer on a system with pumped-storage plant. IEEE Transactions on PWRS, 1988, 3(1), 80-86.

13 Hsu. Y. Y., Huang, P. H.. Lin, C. J. and Huang, C. T., Oscillatory stability considerations in transmission expansion planning. IEEE Transactions on PWRS, 1989, 4(3), 11101114

14 Greene, E. R., Panel on transmission impacts related to siting locations on non-utility generation: NUG siting affects the interchange flow exposure to bottlenecks. Paper 94 SM 523-1, presented at the IEEE/PES Summer Meeting. 1994.

$15 \mathrm{Hsu}, \mathrm{Y}$. Y.. Frequency domain analysis of power system dynamic stability, Research report of Taiwan Power Company, 1985.

16 Zhou, E. Z., A study of the AESOPS/PEALS algorithms. International Journal of Electrical Power and Energy. Sistems, 1992. 14(6), 402410. 